a larger group of individuals who attend these venues may be addressed.

Disclosure No significant relationships.

\section{P709 ABNORMAL CERVICAL SCREENING TEST AND SEXUALLY TRANSMITTED INFECTIONS IN WEST AFRICA'S FEMALE SEX WORKERS}

${ }^{1}$ Ibrahima Téguété* ${ }^{2}$ ' $F$ atoumata Korika Tounkara, ${ }^{3}$ Fernand Guédou, ${ }^{4}$ Bintou Dembele, ${ }^{5}$ Michel Alary. ${ }^{1}$ Gabriel Toure Teaching Hospital, Bamako, Mali; ${ }^{2}$ Axe Santé des Populations et Pratiques Optimales en Santé, HSS, Social and Preventive Medicine, Québec, Canada; ${ }^{3}$ Dispensaire IST, Cotonou, Benin; ${ }^{4}$ ARCAD/SIDA, Bamako, Mali; ${ }^{5} \mathrm{CHU}$ de Quebec Université Laval, Quebec, Canada

\subsection{6/sextrans-2019-sti.774}

Background Cervical cancer is the most common cancer in women in Sub-Saharan Africa. The situation is worst among female sex workers (FSW), a population with poor access to quality reproductive health services. This study aimed to: (1) estimate the prevalence of abnormal cervical screening test (ACST) and (2) assess the association between ACST and sexually transmitted infections (STIs)/lower genital tract infections (LGTIs) among FSW in Cotonou (Benin) and Bamako (Mali).

Methods We conducted a cross-sectional study among nonpregnant FSW aged 18 to 64 years from April 2017 to February 2018. We used a peer recruitment sampling strategy in two West African cities. Visual inspection with acetic acid (5\%) and with Lugol's iodine (VIA/VIL) were performed to screen for cervical cancer. Women were also screened for STIs/LGTIs, specifically those with Trichomonas vaginalis (TV), Candida albicans (CA), Chlamydia trachomatis (CT), Neisseria gonorrhoeae (NG) and bacterial vaginosis (BV). ACST prevalence was computed and its association with STIs/LGTIs was assessed using multivariate logistic regression.

Results ACST prevalence was $20.2 \%$ among 312 FSW in Benin Vs. $10.5 \%$ among 353 FSW in Mali. Of these, 91.2\% never had cervical screening. Mean age at sexual debut was $16.3 \pm 3.0$ years. The overall STIs/LGTIs prevalence rates were: TV, 2.7\%; CT, 10.9\%; NG, 19.4\%; HIV, 23.0\%; CA, $7.4 \%$ and $\mathrm{BV}, 37.1 \%$. CA was the only infection associated with ACST $(\mathrm{aOR}=4.03$; 95\%CI: 1.77-9.17). Also, there was a statistical association between a coinfection by CA-TV and ACST $(\mathrm{aOR}=3.21 ; 95 \% \mathrm{CI}$ : 1.47-7.01). Finally, age at sexual debut $<10$ years old was significantly associated with ACST $(\mathrm{aOR}=6.10 ; 95 \% \mathrm{CI}: 1.19-31.21)$.

Conclusion The prevalence of ACST and STIs/LGTIs was very high; there is an obvious need to improve the diagnostic capability and the clinical management of these conditions among FSW of Sub-Saharan Africa.

Disclosure No significant relationships.

\section{P710 EPIDEMIOLOGY OF ABNORMAL CERVICAL CYTOLOGY IN FEMALE SEX WORKERS IN MALI, WEST AFRICA}

${ }^{1}$ Fatoumata Korika Tounkara*, ${ }^{2}$ Ibrahima Téguété, ${ }^{3}$ Fernand Guédou, ${ }^{4}$ Bintou Dembele, ${ }^{5}$ Michel Alary. 'Axe Santé des Populations et Pratiques Optimales en Santé, HSS, Social and Preventive Medicine, Québec, Canada; ${ }^{2}$ Gabriel Toure Teaching Hospital, Bamako, Mali; ${ }^{3}$ Dispensaire IST, Cotonou, Benin; ${ }^{4}$ ARCAD/SIDA, Bamako, Mali; ${ }^{5} \mathrm{CHU}$ de Quebec Université Laval, Quebec, Canada

10.1136/sextrans-2019-sti.775
Background To our knowledge, no previous study has been carried out about cervical cancer in female sex workers (FSW) in Mali. The objective of this work was to estimate the prevalence and risk factors of cervical precancerous lesions among FSW in Mali.

Methods We carried out a cross-sectional study from November 2017 to February 2018 in Mali. Screening for cervical cancer was performed with Papanicolaou test. HIV and syphilis serology, direct examination of vaginal smears for vaginitis and bacterial vaginosis and nucleic acid amplification tests for gonorrhea and chlamydia were also carried out. We calculated the prevalence rates. Risk factors of low grade squamous intraepithelial lesions (LSIL), and high grade squamous intraepithelial lesion (HSIL) were identified using polytomous logistic regression. Adjusted odd ratios (aOR) with 95\% confidence intervals $(95 \% \mathrm{CI})$ were estimated.

Results Among the 353 women enrolled in the study, 20.4\% were HIV seropositive, whereas $53.8 \%$ had at least one of other sexually transmitted infections (STIs), including trichomoniasis at 3.7\%; chlamydia, $14.0 \%$; gonorrhea, 24.4\%, syphilis, $3.1 \%$ and bacterial vaginosis (Nugent score $\geq 7$ ), $23.5 \%$. The mean age at first sexual intercourse was $15.3 \pm 2.9$ years. Fifty-eight women had abnormal cytology/histology (17.4\%; 95\% CI: $13.3-21.4 \%)$ and only $8.8 \%$ of FSW had at least one cervical screening test in the past year. Among all participants, $2.7 \%$ presented atypical glandular cells of undetermined significance (AGUS), $11.3 \%$ with LSIL, and 3.3\% with HSIL. Risk factors of LSIL were HIV infection $(\mathrm{aOR}=$ 1.53; 95\%CI: 1.02-2.30) and age at sexual debut $<10$ years $(\mathrm{aOR}=4.52 ; 95 \% \mathrm{CI}: 1.11-18.45)$. Factors associated with HSIL were self-reported previous STIs $(\mathrm{aOR}=4.92 ; 95 \% \mathrm{CI}$ : $1.15-21.09)$ and current syphilis $(\mathrm{aOR}=8.12$; 95\%CI: $1.86-$ 35.39).

Conclusion Low and high grades cervical squamous intraepithelial lesions have different risk factors profile in Malian FSWs.

Disclosure No significant relationships.

\section{P712 "YOU NEED A CASH BUFFER": MALE SEX WORK AND CONDOM USE IN THE ERA OF HIV PRE-EXPOSURE PROPHYLAXIS}

${ }^{1}$ Denton Callander*, ${ }^{2}$ Stephen Bell, ${ }^{3}$ Victor Minichiello, ${ }^{2}$ Ryan Deveau, ${ }^{2}$ Garrett Prestage, ${ }^{4}$ Basil Donovan. ${ }^{1}$ New York University, School of Medicine, New York, USA; ${ }^{2}$ UNSW Sydney, The Kirby Institute, Sydney, Australia; ${ }^{3}$ La Trobe University, Melbourne, Australia; ${ }^{4}$ UNSW Sydney, Kirby Institute, Sydney, Australia

\subsection{6/sextrans-2019-sti.776}

Background HIV pre-exposure prophylaxis (PrEP) has reshaped condom use practices in many contexts, but little is known about its impact on commercial sex encounters between men. This study investigated condom use in Australian male sex work.

Methods During 2017-2018, we undertook a mixed-method ethnographic study of male sex work in Australia, working with male sex workers $(n=32)$ and clients of sex work $(n=3)$ to collect online sex work profile data and conduct individual and group interviews. These data were analyzed topically with a focus on condom use.

Results In November 2018, online data were scraped from 236 male sex work profiles: $2.1 \%$ expressed an explicit requirement for condom use, down from 14.2\% in June 2017 